\title{
INFÂNCIA, EDUCAÇÃO E MEIO AMBIENTE: REPRESENTAÇÕES DE CRIANÇAS DA RESEX DO LAGO DO CUNIÃ/RO
}

\author{
Diógenes Valdanha Neto \\ Dulce Consuelo Andreatta Whitaker ${ }^{2}$ \\ Elis Cristina Fiamengue ${ }^{3}$ \\ Valéria Oliveira de Vasconcelos ${ }^{4}$
}

Resumo: Nas Ciências Sociais já há algum tempo que as crianças foram alçadas à categoria de sujeitos da pesquisa. Nesse contexto, este artigo comunica resultados de uma investigação socioambiental realizada com crianças residentes na Reserva Extrativista (RESEX) do Lago do Cuniã/ RO. O objetivo principal foi o de compreender melhor as representações de crianças da comunidade sobre a escola e o meio ambiente local, visando a permitir a emersão de elementos do imaginário infantil. Foram coletados, ao todo, 15 desenhos de estudantes das séries iniciais do Ensino Fundamental da escola da comunidade sobre: 1) a escola local e 2) o meio ambiente da comunidade. Os mais expressivos foram selecionados para as análises, a saber: 05 da escola e 04 do meio ambiente. Os dados revelam como principais resultados a forte marca da seriação escolar no imaginário infantil, e o afeto para com o meio ambiente; além de uma vastidão de conhecimentos sobre a biodiversidade local que é retratada explicitamente. Esses elementos são discutidos à luz da sociologia rural e da perspectiva da educação do campo, na defesa da possiblidade de realização de uma conservação ambiental atrelada à reforma agrária e à valorização dos modos de vida tradicionais.

\footnotetext{
Biólogo. Mestre em Educação Escolar. Doutorando em Educação. Professor da Universidade Federal do Triângulo Mineiro (UFTM). E-mail: diogenesvn@gmail.com. Agradece à FAPESP pela concessão de bolsa de mestrado, processo número 2012/18926-4.

Socióloga, Mestre e Doutora em Sociologia. Professora aposentada da Universidade Estadual Paulista "Júlio de Mesquita Filho" (UNESP/FCLAR) e professora da Universidade de Araraquara (UNIARA).

Socióloga. Mestre e Doutora em Sociologia. Professora da Universidade Estadual de Santa Cruz (UESC). E-mail: eliscf@gmail.com

${ }^{4}$ Educadora Popular. Mestre em Educacão Especial e Doutora em Educação. Professora do Programa de PósGraduação em Educação do Centro Universitário Salesiano de São Paulo (UNISAL - Americana). E-mail: Graduação em Educação
}

Palavras-Chave: Educação do Campo; Meio Ambiente; Amazônia; Infância; Povos Tradicionais.

ABSTRACT: In the Social Sciences there has been a while since the children were raised to the category of research subjects. In this context, this article reports the results of a socioenvironmental investigation carried out with children living in the Extractive Reserve Lago do Cuniã/RO. The main objective was to better understand the representations of children of the community about the local school and environment, in order to allow the emergence of elements of the children's imagination. A total of 15 drawings were collected from students in the elementary school on: 1) the local school and 2) the community environment. The most expressive ones were selected for analyses, namely: 05 of the school and 04 of the environment. The data reveal as main results in the children's imagination the strong mark of school's division in classes, and the affection towards the environment; in addition to a vast knowledge of local biodiversity that is explicitly portrayed. These elements are discussed in the light of rural sociology and the perspective of rural education, in defence of the possibility of achieving environmental conservation linked to agrarian reform and the valorisation of traditional ways of life.

Keywords: Rural Education; Environment; Amazon; Childhood; Traditional People.

\section{INTRODUÇÃo}

Nas Ciências Sociais já há algum tempo as crianças foram alçadas à categoria de sujeitos da pesquisa (SARMENTO, 2011; FIAMENGUE, 1998). Florestan Fernandes (1961) foi pioneiro na pesquisa sobre grupos infantis com "As Trocinhas do Bom Retiro", na qual ousa ouvir às crianças e com elas aprender, já nos anos 40 do século passado. Mais recentemente a sociologia parece ter redescoberto a infância e tem se dedicado a compreender o universo infantil desde uma perspectiva mais abrangente. Este artigo partilha desse pressuposto e busca também ampliar essa perspectiva para questões socioambientais.

A luta pela terra e pela reforma agrária passa pelas esferas da gestão educacional e ambiental, e estudos anteriores já demonstraram que as crianças guardam a memória dos processos de luta pela terra e conseguem enxergar a escola criticamente (FIAMENGUE, 1998). Martins (1993) destaca a importância de figurar entre as pesquisas sociológicas a expressão, 
seja ela qual for, dos sujeitos que supostamente têm menos a dizer. Aqueles que estão à margem de certos processos decisórios. Demonstra, a partir de diálogos com crianças de diversas áreas rurais, que a infầncia pode ser caracterizada diferentemente pelos próprios sujeitos que a vivem, dependendo principalmente das vias de entrada do capital na vida comunitária desses sujeitos. A busca, por meio do trabalho, de transformação da realidade marcada de carências é expressa pelas crianças como elemento que configura seus horizontes e utopias, dando sentido a suas práticas cotidianas de trabalho.

A pesquisa educacional empírica de Leite (1996), com crianças de uma localidade rural brasileira, demonstra, a partir da observação e escuta atenta aos sujeitos da investigação, que elas aprendem em comunhão com os adultos a valorizar e gostar de suas práticas possíveis do cotidiano, e a valorizar a escola em seu papel de ensino sistematizado - apesar do pouco espaço que comumente a instituição abre para a manifestação das crianças. Sobre aspectos do mundo infantil, em específico o rural, que a escola tem dificuldade de dialogar, Leite (1996, p. 91/2) destaca:

A insensibilidade com a cultura e a linguagem da criança faz com que as instituições identifiquem como carência aquilo que é, na realidade, diferença. Quero então reforçar: diferentemente do que defendem as teorias da privação cultural, as crianças-sujeitos desta pesquisa [rurais] não são carentes nem estão em falta.. Vivem seus diferentes papéis em família; estão inseridas na comunidade e no funcionamento desta; têm espaço para brincar; possuem inúmeros saberes; são educadas para o trabalho, para gostar do que fazem, parecendo viver a possibilidade de aliar o trabalho ao jogo, estruturando suas relações com a vida, com a produção, e não necessariamente com a reprodução.

Em diálogo com essas experiências investigativas da infância, este artigo é resultado da interlocução entre o autor e autoras, partilhando de suas diferentes trajetórias e experiências de pesquisa e se propondo a discutir e analisar desenhos daquelas que denominamos "crianças da floresta" coletados durante pesquisa de campo realizada na Reserva Extrativista (RESEX) do Lago do Cuniã, localizada no estado de Rondônia - Amazônia brasileira-, durante o ano de 2013. O objetivo principal foi o de compreender melhor as representações de crianças da comunidade sobre a escola e o meio ambiente local, visando a permitir a emersão de elementos do imaginário infantil. Essas representações poderão subsidiar discussões e tomadas de decisões da gestão educacional e ambiental de seu território.

A Reserva em questão é fruto de um longo processo de luta social pelo direito ao uso da terra, que se iniciou nos primeiros anos da década de 1980 com a tentativa de expulsão dos moradores da área movida pela extinta Secretaria Especial do Meio ambiente para a criação de uma Reserva Ecológica - uma área especialmente protegida para a conservação da natureza na qual não é permitida a residência de grupos humanos (SILVA, 1994). A população local, formada por caboclos extrativistas, em sua maioria ex seringueiros, articulou-se e de diversas maneiras pressionou o poder público pelo direito à permanência na área. Como resultado desses esforços, em 1999 foi formalizada a criação da Reserva Extrativista como uma proposta de conciliar a proteção tanto ao ecossistema quanto à cultura tradicional ali existente. A Figura 1 localiza a RESEX do Lago do Cuniã no mapa nacional.

Figura 1 - Mapa da RESEX do Lago do Cuniã, localizando-a no plano nacional.

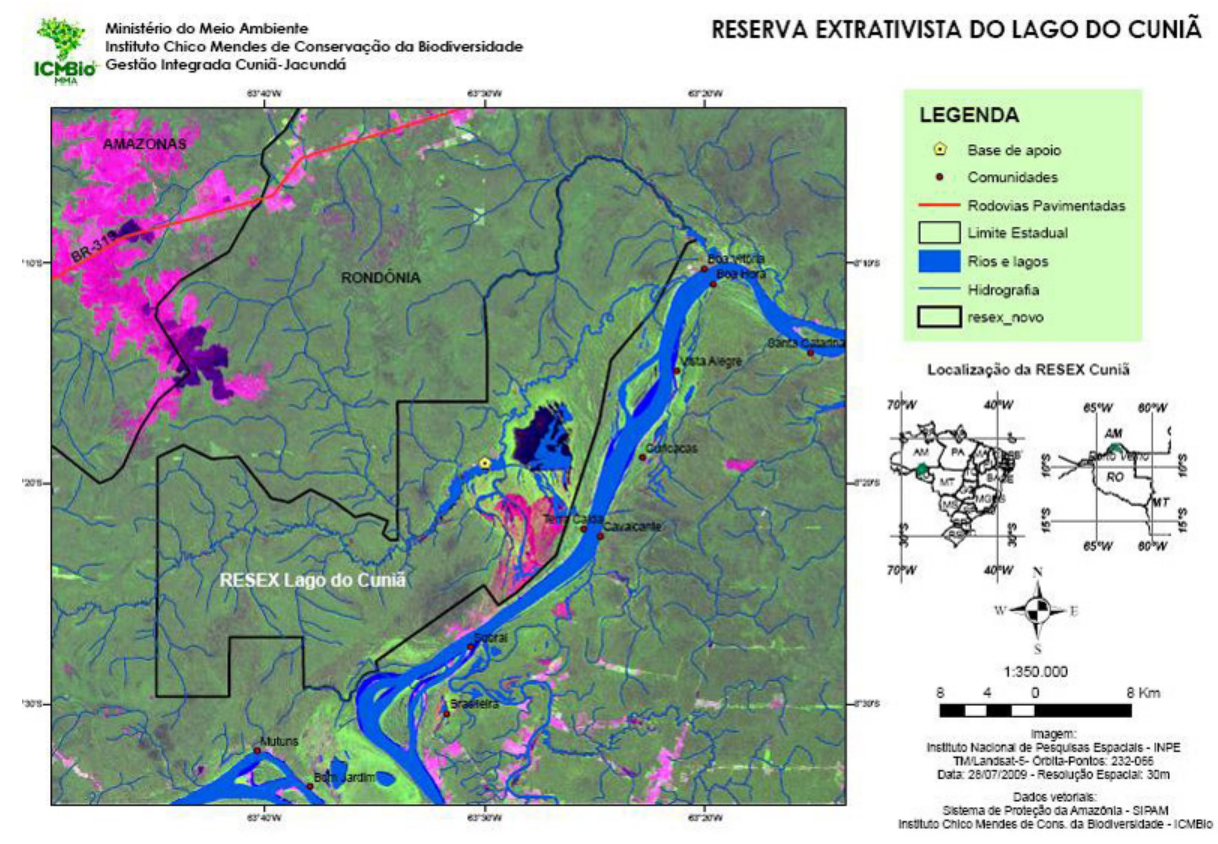

Fonte: $\mathrm{ICMBio}^{5}$

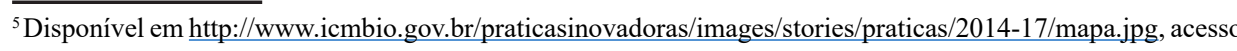
em 20/07/2018. 


\section{Metodologia}

Entre os meses de maio e junho de 2013, pesquisas de campo foram realizadas na RESEX visando compor um projeto investigativo maior, cujo principal relatório pode ser acessado em Valdanha Neto (2014). Todavia, os dados aqui discutidos extrapolavam os limites da discussão que se propunha naquele momento, e optou-se por analisá-los neste texto específico.

Os desenhos foram realizados em dois momentos, ambos em sala de aula, durante o mês de junho de 2013, com estudantes dos terceiros, quartos e quintos anos do Ensino Fundamental. No primeiro momento o professor responsável pela turma solicitou que os alunos fizessem desenhos da escola da comunidade e, estrategicamente, para uma maior atenção nas elaborações, afirmou que eles seriam utilizados como atividade avaliativa da disciplina de Artes. O segundo momento ocorreu no Dia Mundial do Meio Ambiente, quando os alunos foram solicitados a produzir desenhos sobre o "Meio Ambiente" da Reserva. Foram coletados, ao todo 15 desenhos sobre a escola, e 08 sobre o Meio Ambiente, dos quais foram selecionados os mais expressivos e detalhados para compor este artigo.

A análise de desenhos não é unívoca. E tampouco é possível uma análise aprofundada dessa natureza sem contextualização. Dessa forma, é importante lembrar que o contexto e histórias de vida que perpassam a comunidade dessas crianças que desenharam são previamente conhecidas, como apresentado brevemente na introdução, e permeiam nossas análises dessas representações.

A respeito dos desenhos realizados por crianças, em pesquisas anteriores com a utilização da técnica, Whitaker (2002, p. 15) afirma que estes "revelaram-se fonte inesgotável de representações sobre o processo cultural e sobre as relações complexas dos homens rurais entre si e principalmente entre os homens [e mulheres] e a natureza no meio rural". Revelando um acúmulo na sedimentação desta técnica como fonte de investigações científicas.

Primeiramente serão apresentados os desenhos referentes à escola da comunidade e algumas análises. Posteriormente serão comunicados os desenhos relativos ao Meio Ambiente da comunidade.

\section{A escola}

O Desenho 01 foi realizado por uma menina que representou a sala da diretoria separada da escola - representação que não condiz com a realidade física, pois a diretoria é uma das salas que compõem o prédio único da escola. Todavia, a criança parece captar uma separação entre as instâncias burocráticas e da prática escolar, e representa a escola como maior que a diretoria.

A escola é vista de fora, mas com portas, e é gigantesca - ver em comparação com a árvore - o que sugere a importância que esta instituição tem no imaginário da garota. Há uma demarcação explícita da separação entre as classes.

Desenho 01 - primeira representação da escola.

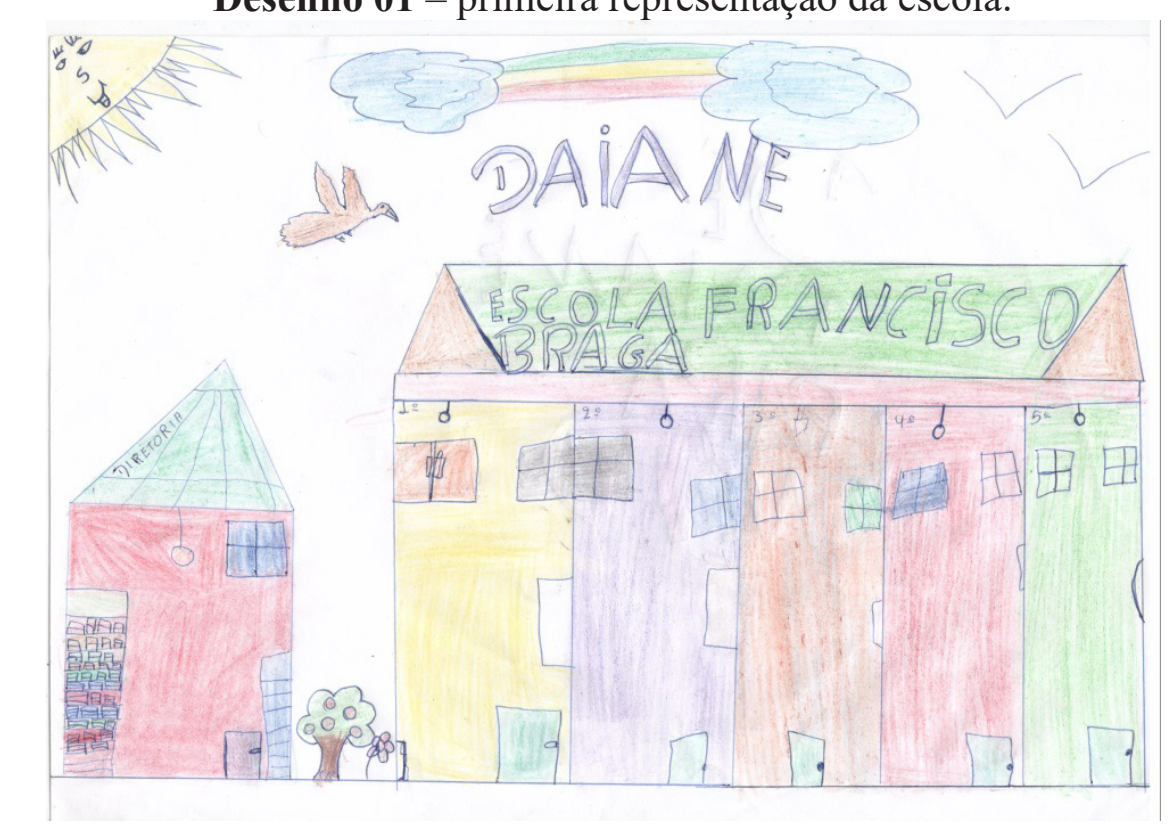

O Desenho 2 reforça a questão da dimensão da escola e a criança responsável pela gravura também vê a escola de fora, porém de um ângulo diferente da criança do Desenho 1. A árvore também está em tamanho diminuto em comparação com o prédio e há uma representação em perspectiva da mata florestal que se encontra atrás da escola.

O Desenho 03 aparece em tons mais claros O prédio ao lado da escola é o refeitório. Vários desenhos incluíam o refeitório, podendo representar a dimensão que este espaço tem no imaginário referente à vida escolar. As cores do refeitório são mais fortes do que as da escola, o que também não condiz com a materialidade, uma vez que a escola é pintada em amarelo forte, e o refeitório é de madeira em tons claros de azul e branco. 
Desenho 02 - segunda representação da escola.

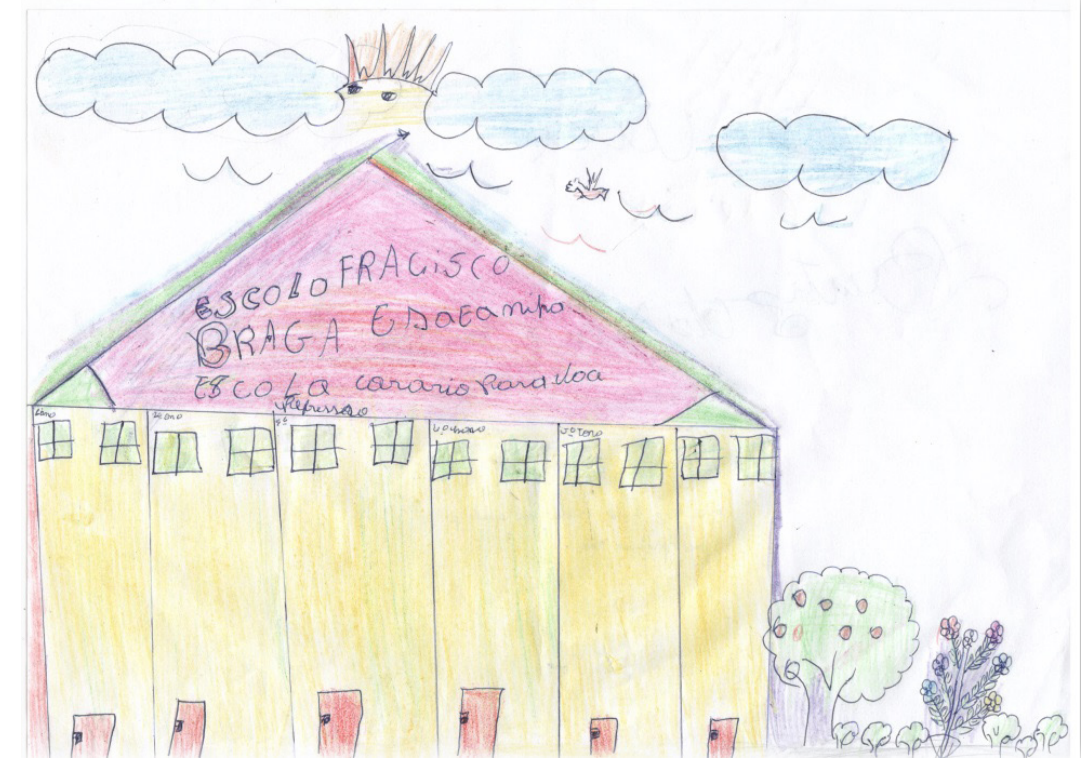

Desenho 03 - terceira representação da escola.

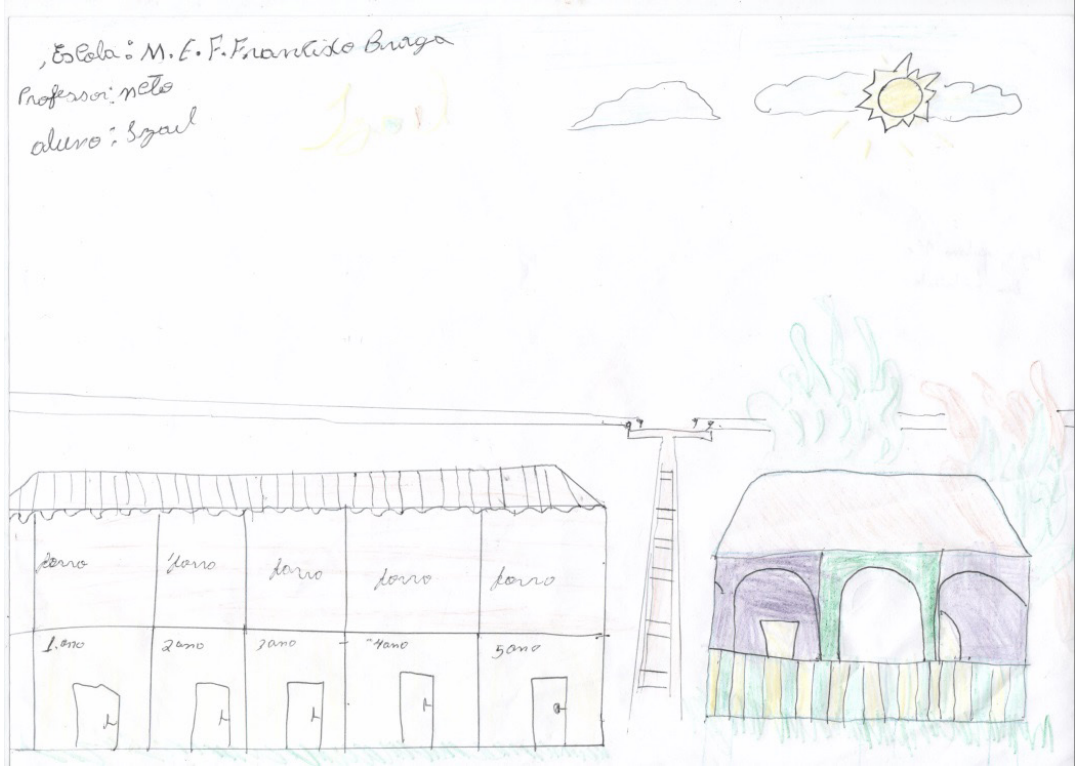

Desenho 04 - quarta representação da escola.

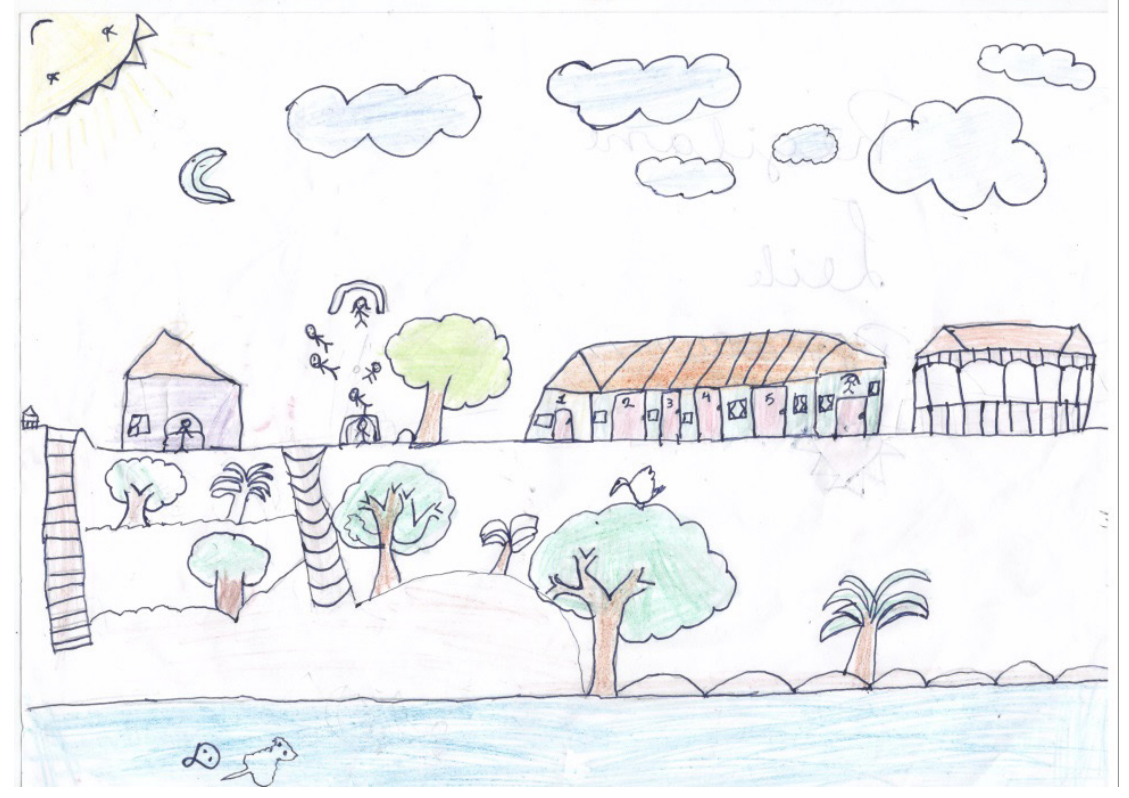

Desenho 05 - quinta representação da escola.

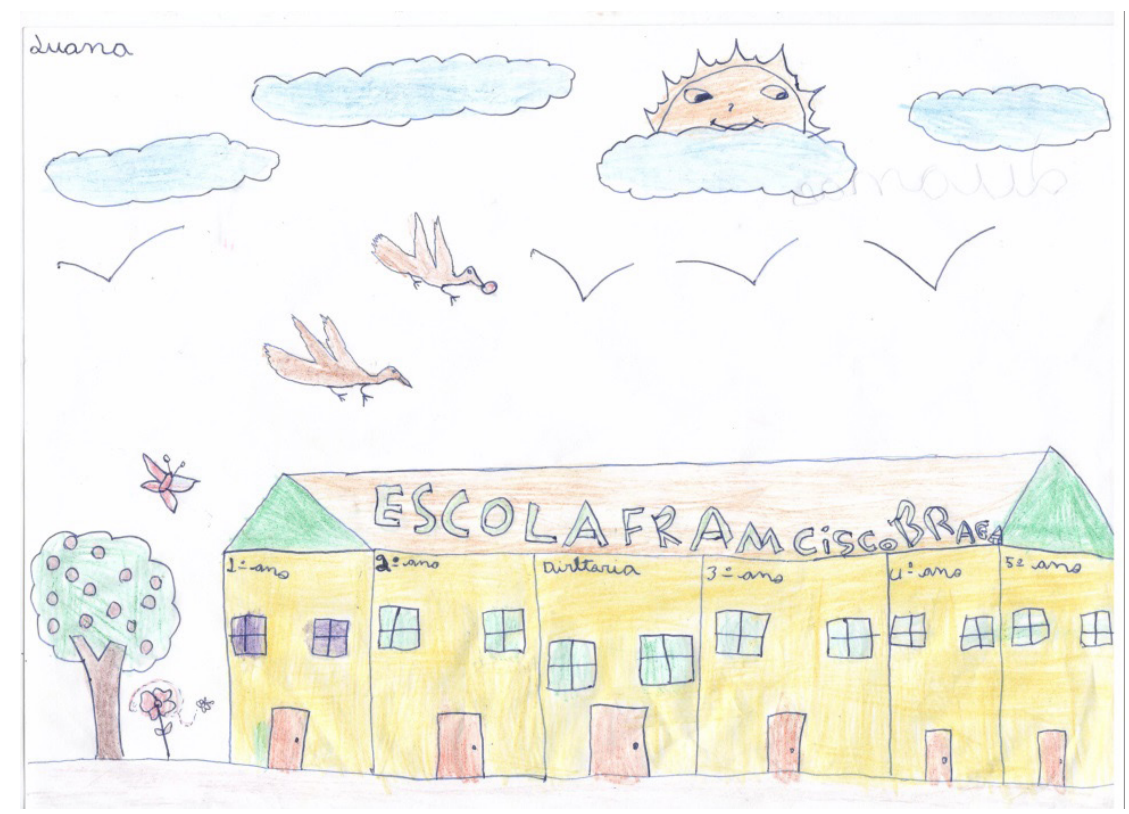


O desenho 04 amplia a perspectiva da escola e retrata também o lago que dá nome à Reserva em que vivem as crianças. O refeitório escolar é representado maior do que a própria escola (talvez, mais importante?). Para esta criança a escola não é representada de maneira separada do ambiente circundante e as árvores estão maiores que a instituição. Ilustra algumas crianças jogando futebol, em uma perspectiva peculiar, ao lado do prédio, e as escadarias que conectam o lago à terra figuram também como parte do meio. O sol sorri e a lua se mostra presente. Há vida nas águas e na terra. E vida diversa!

No Desenho 05 há uma espécie de animação implícita. As janelas e as portas representadas pela criança assemelham-se a olhos e bocas. $\mathrm{Na}$ concretude, as janelas são paralelas entre si e também com a as portas. Tudo é grande: escola, árvore, flor aves, nuvens e sol. A seriação das salas é, igualmente, muito demarcada, mesmo que na prática a junção de turmas (multiseriação) seja uma constante no cotidiano da instituição.

\section{O MEIO AMBIENTE}

Com relação às representações do Meio Ambiente entre as crianças, houve uma confecção menor de desenhos por conta da coleta de dados ter sido realizada com um conjunto menor de alunos e alunas. Todavia, há elementos reveladores sobre o imaginário infantil local sobre seu contexto de vida.

O desenho 06 retrata o ambiente local com uma diversidade enorme de vida! A criança representa os seres humanos totalmente inseridos no meio e há uma atmosfera de felicidade envolvida, explícita pelo colorido do arcoíris entre nuvens. As cores são variadas e há abundância e variedade de alimentos. A riqueza de detalhes apresentada no desenho revela o profundo conhecimento desta criança sobre o lugar, bem como sobre os processos de produção da vida material e afetiva. Cultura e natureza aparecem fusionadas, como de fato o são, conforme as discussões da antropologia e das ciências em geral (WHITAKER; BEZZON, 2006). Importante notar também a diversidade e abundância de frutos nas árvores.

O Desenho 07 traz menos cores, mas as frutas (alimento) aparecem em formato de corações, manifestando novamente a relação afetuosa com a natureza que nutre. O ser humano é ilustrado como um grande elemento do meio (atentar para seu tamanho em relação às árvores). A casa também é ambiente, e a antena parabólica (lazer) permeia sua relação tradicional com a natureza. Não há contraposição entre o elemento tecnológico e os elementos naturais.
Desenho 06 - primeira representação do Meio Ambiente da comunidade.

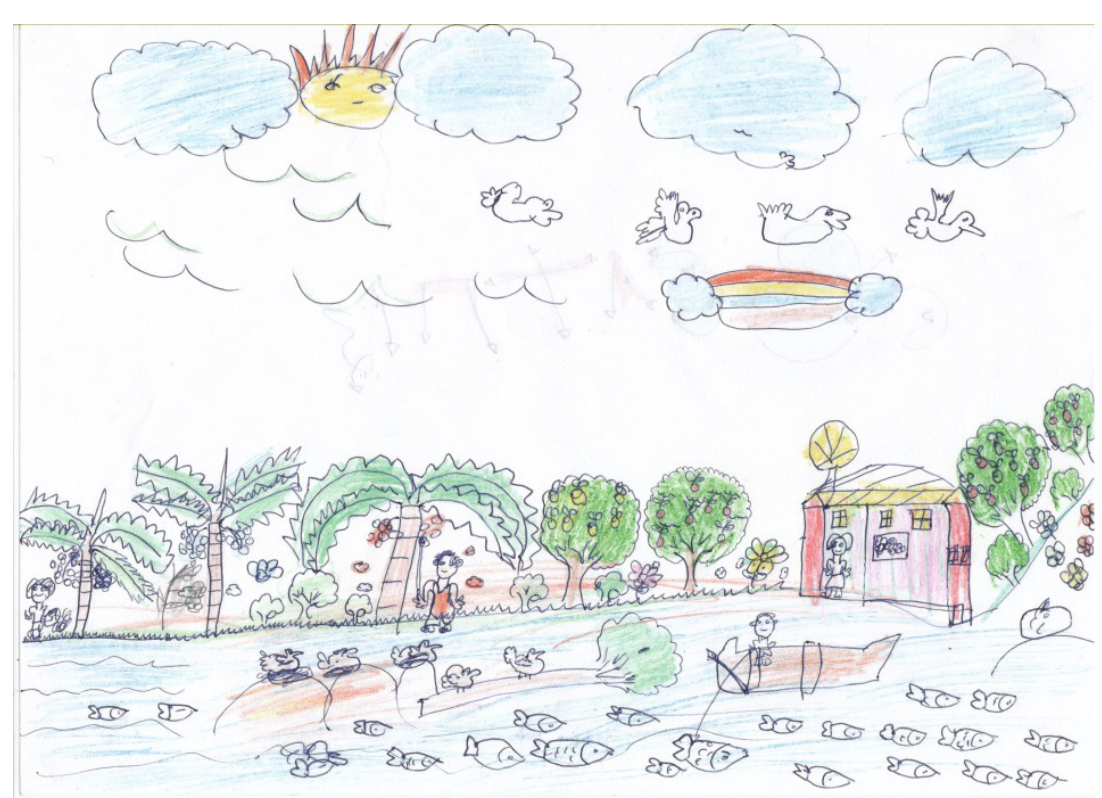

Desenho 07 - segunda representação sobre o Meio Ambiente da comunidade.

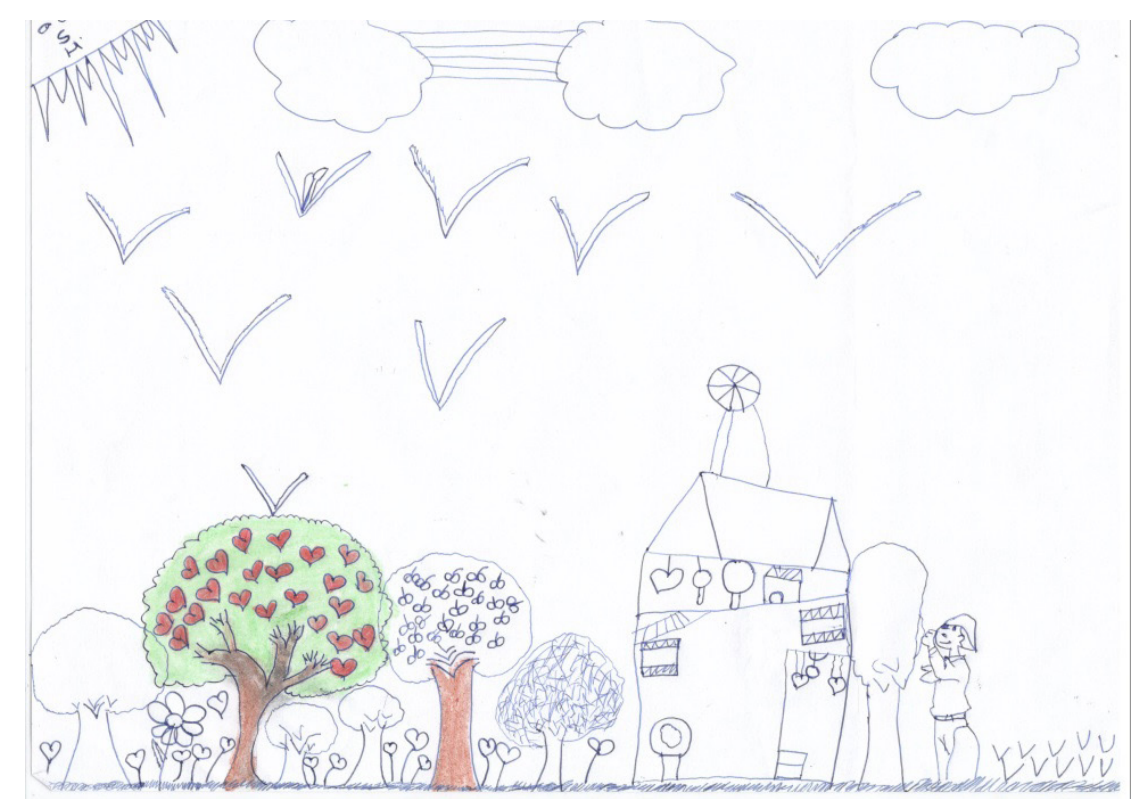


No Desenho 08 observa-se a representação do estudante permeada pela cerca que isola sua morada do restante da comunidade. A família da criança cria gado e vive na única porção de terra cercada dentro da Reserva, o que se evidencia como um aspecto forte na percepção de sua relação com o meio. Espaço para árvores há apenas fora das cercas.

O último desenho selecionado referente ao meio ambiente da comunidade (Desenho 09) e reafirma a presença da parabólica no imaginário das crianças. A televisão manifesta-se como um item importante, por permitir um tipo específico de lazer, e é também recente, uma vez que a energia elétrica chegou à Reserva apenas no ano de $2009^{6}$. O lazer também é representado, de outra maneira, pela rede nas sombras das árvores. A diversidade de frutos, plantas e peixes revela o grande conhecimento que essas crianças detêm sobre seu ambiente, a natureza que os circunda. Os desenhos também revelam a fartura da natureza do lugar. A profusão de árvores, frutas, flores, aves e de peixes é marcante em todos os desenhos coletados.

Desenho 08 - terceira representação do Meio Ambiente da comunidade.

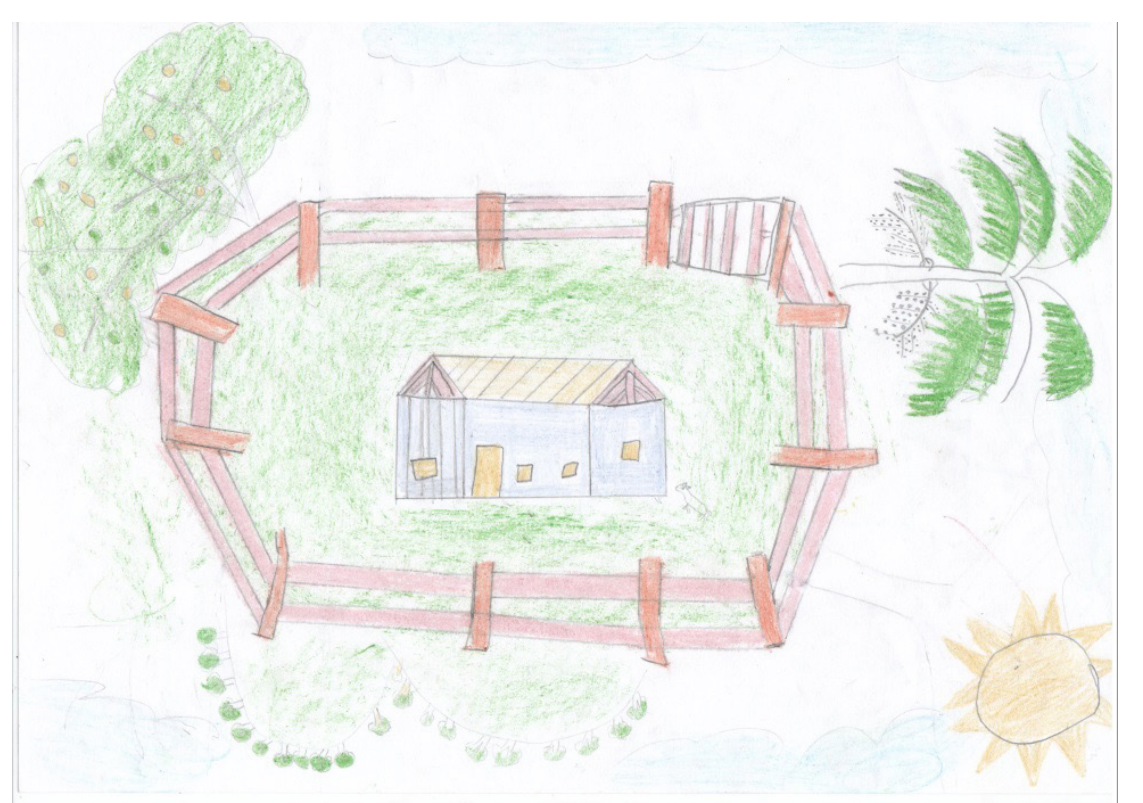

'Iniciativa do programa de eletrificação rural "Luz para Todos", do governo federal. Programa lançado em 2003 em meio aos avanços nos direitos populares que permearam a gestão do Partido dos Trabalhadores no país.

Desenho 09 - quarta representação sobre o meio ambiente da comunidade.

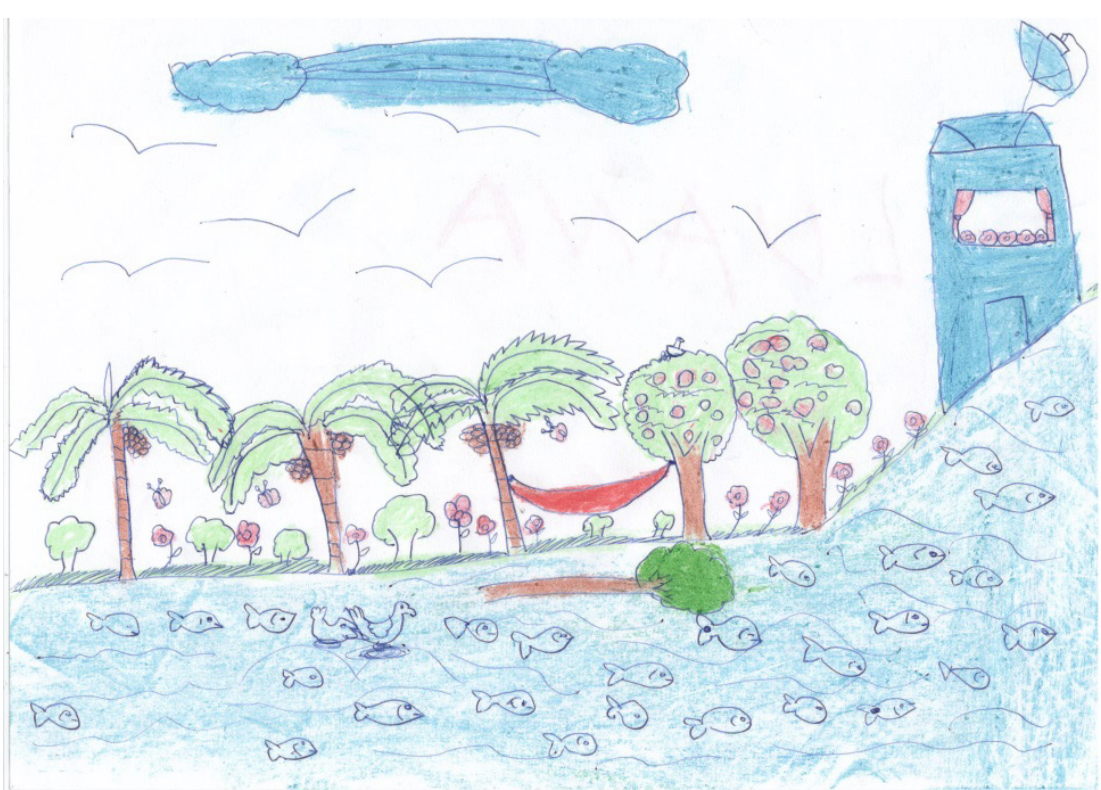

\section{TECENDO RELAÇões}

Consideramos as representações aqui apresentadas como de extrema relevância para contribuir com uma compreensão mais completa da complexidade que envolve as questões educacionais e do meio ambiente na comunidade. Pesquisas anteriores desenvolvidas no mesmo local captaram elementos acerca das esferas escolares e ambientais, mas há defasagem quanto à escuta que propicia a emersão do que esses sujeitos, as crianças, têm a dizer.

Com relação à educação escolar local, a pesquisa de Valdanha Neto (2014) constatou desafios expressos por professoras e professores com relação ao diálogo da instituição com a cultura local. Todavia, a questão da seriação para as e os profissionais escolares é sempre apresentada como algo positivo - uma conquista da comunidade. Vale problematizar essa assertiva, como faz Hage (2014), uma vez que a educação do campo não necessita ser seriada para ter qualidade. Essa é uma imposição de um sistema de gestão limitado para compreender o desenvolvimento infantil, sobretudo no mundo rural.

Arroyo (2010) destaca que é típico que as crianças do campo se 
eduquem entre mais velhas e mais novas, e que a imposição da seriação é muitas vezes fator de ruptura de uma lógica cultural diferente da operação urbana. Os desenhos aqui apresentados sobre a escola trazem como aspecto explicitamente salientado a divisão da escola em séries. Por vezes, há no imaginário das crianças mais divisões do que na realidade: uma vez que a comunidade sofre com falta de docentes e comumente suas aulas são multisseriadas. Ademais, há na realidade quatro salas de aula na escola, $\mathrm{e}$ é tácito entre as e os professores que o primeiro e segundo ano do Ensino Fundamental terão aulas juntos. Entretanto, comumente os desenhos apresentam cinco salas de aula totalmente dissociadas.

Os processos educativos acontecem em diversas instituições e momentos da vida social, como na família, na igreja e também no trabalho. Concebemos a escola comunitária como local de síntese e diálogo dessas diversas produções de conhecimento com o arbitrário cultural dominante (BOURDIEU; PASSERON, 1992) que possibilita a esses sujeitos se moverem por entre as frestas da sociedade de classes que vivemos, e conquistarem direitos e dignidade.

Assim muitos são os desafios colocados para a escola do campo. Como os dados aqui apresentados sugerem, a gestão educacional hegemônica da seriação pode ser colocada em xeque por meio da cultura de socialização predominante no mundo rural. Também, e além, os desenhos do meio ambiente da comunidade revelam o grande conhecimento da biodiversidade circundante que essas crianças têm. Essas percepções, chamadas por Freire (2013) de "saberes da experiência", comumente são invizibilizados nas instituições de ensino urbanocêntricas.

Ademais, é fundamental enfatizar que essas constatações e defesas de responsabilidades da escola pública do campo com o respeito e valorização da diversidade cultural do país não podem ser utilizadas como um fardo a mais para ser colocado sobre as e os profissionais da educação. A situação atual é de calamidade do investimento público na escolarização dos filhos e filhas da classe trabalhadora do país, sendo agravada após o golpe jurídicoparlamentar de 2016, que aprovou o congelamento de recursos para setores sociais de gastos públicos por 20 anos na famigerada PEC 55. Enquanto, concomitantemente, a concentração de renda se acentua ${ }^{7}$. É contra essa realidade que os dados aqui apontam, contra a desumanização imposta pelo sistema econômico.

Acerca da esfera ambiental, há desafios equivalentes. As populações tradicionais da Amazônia tem sentido a pressão crescente do avanço do agronegócio por entre a floresta. Até mesmo as Unidades de Conservação, como as Reservas Extrativistas, não estão imunes. Mas nossos dados revelam a relação afetiva com o território, o amor pelo lugar que nutre e acolhe as crianças, o que pode significar resistência.

Em pesquisa anterior, Gomes, Valdanha Neto e Platzer (2015)demonstraram, por meio de investigação com questionários, que há uma variedade de concepções de Meio Ambiente entre as e os moradores do Lago do Cuniã, incluindo manifestações que destacam o ser humano como parte do ambiente. Contudo, o instrumento utilizado pelos autores não permitiu captar toda riqueza de elementos que as crianças manifestam por meio dos desenhos. Sobretudo as representações afetivas.

\section{CONSIDERAÇõEs FINAIS}

Este artigo compõe um programa de pesquisas para a compreensão de uma singularidade - a comunidade da Reserva Extrativista do Lago do Cuniã - que traz elementos para um entendimento de aspectos mais gerais sobre as políticas ambientais, educacionais e de desenvolvimento rural sendo desenvolvidas no Brasil.

Atentar à voz de crianças rurais, sobretudo por meio de suas formas de representações mais fluidas. Os dados apresentados revelam a força com que esses sujeitos captam aspectos de ruptura e também de harmonização com sua cultura tradicional. A escola ainda é um ente diferenciado de seu modo de se relacionar, possivelmente essa é uma barreira intransponível dada a natureza da instituição, mas que pode ser minimizada. O meio ambiente é retratado como parte de quem são, não há muitas distinções, com exceção das cercas que chegam acompanhadas pela produção pecuária, nelas não cabe a floresta.

Frente a essas constatações, faz-se necessário reforçar a defesa por uma educação e uma escola do campo próprias, singulares, calcadas nas demandas dos movimentos sociais rurais e atreladas às perspectivas emancipatórias da população rural frente à dominação do capital - tal como a agroecologia. Conforme pontua Whitaker (2008), uma escola que faça forças opostas às ideologias urbanocêntricas, etnocêntricas e sociocêntricas que permeiam a educação pública, e que contribua para a construção de uma sociedade igualitária e respeitando a multiplicidade cultural do país.

\section{REFERÊNCIAS}


ARROYO, M. G. Escola: terra de direito (prefácio). In: ANTUNESROCHA, M. I.; HAGE, S. M. (orgs.). Escola de direito: reinventando a escola multisseriada. Belo Horizonte: Autêntica Editora, 2010.

BOURDIEU, P.; PASSERON, J. A reprodução. 3.ed. Rio de Janeiro: Francisco Alves, 1992.

FERNANDES, F. Folclore e mudança social na cidade de São Paulo. São Paulo: Ed. Anhembi, 1961.

FIAMENGUE, E. C. Infância e diversidade: representações de crianças em um assentamento de trabalhadores rurais. Retratos de Assentamentos, Araraquara, v. 8, p. 9-34, 1998.

FREIRE, P. Pedagogia do Oprimido. 54 edição revista e atualizada. São Paulo: Editora Paz e Terra, 2013.

GOMES, D. F.; VALDANHA NETO, D.; PLATZER, M. B. Leituras de mundo em uma escola na floresta: meio ambiente e educação ambiental entre educandos e educadores de uma reserva extrativista. REMEA - Revista eletrônica do Mestrado em Educação Ambiental, v. 32, n. 01, 2015.

HAGE, S. A. M. Transgressão do paradigma da (multi)seriação como referência para a construção da escola pública do campo. Educação \& Sociedade, v. 35, n. 139, 2014.

LEITE, M. I. F. P. O que falam de escola e saber as crianças da área rural? Um desafio da pesquisa de campo. In: KRAMER, S.; LEITE, M. I. F. P. Infância: fios e desafios da pesquisa. Campinas-SP: Papirus, 1996.

MARTINS, J. S. O massacre dos inocentes: a criança sem infância no Brasil. $2^{a}$ edição. São Paulo: Hucitec, 1993.

SARMENTO, M. J. Conhecer a infância: os desenhos das crianças como produções simbólicas. IN: MARTINS FILHO, A. J; PRADO, P. D. Das pesquisas com crianças à complexidade da infância. Campinas, SP: Autores Associados, 2011
SILVA, J. C. Cuniã: mito e lugar. Dissertação (Mestrado em Geografia Humana). Mimeo. FFLCH/USP, São Paulo-SP, 1994.

PRIMEIRO AUTOR. Dissertação (Mestrado). 2014.

WHITAKER, D. C. A. Introdução. In: WHITAKER, Dulce Consuelo Andreatta (org.). Sociologia Rural: questões metodológicas emergentes. Presidente Venceslau: Letras à Margem, 2002.

WhITAKER, D. C. A.; BEZZON, L. C. A Cultura e o Ecossistema: reflexões a partir de um diálogo. Campinas, São Paulo: Editora Alínea, 2006.

WHITAKER, D. C. A.. O rural-urbano e a escola brasileira. Retratos de Assentamentos, n.11, 2008. 